\title{
Cytometric methods for measuring bacteria in water: advantages, pitfalls and applications
}

\author{
Frederik Hammes • Thomas Egli
}

Received: 24 January 2010 /Revised: 5 March 2010 /Accepted: 8 March 2010 /Published online: 30 March 2010

(C) Springer-Verlag 2010

\begin{abstract}
Rapid detection of microbial cells is a challenge in microbiology, particularly when complex indigenous communities or subpopulations varying in viability, activity and physiological state are investigated. Flow cytometry (FCM) has developed during the last 30 years into a multidisciplinary technique for analysing bacteria. When used correctly, FCM can provide a broad range of information at the single-cell level, including (but not limited to) total counts, size measurements, nucleic acid content, cell viability and activity, and detection of specific bacterial groups or species. The main advantage of FCM is that it is fast and easy to perform. It is a robust technique, which is adaptable to different types of samples and methods, and has much potential for automation. Hence, numerous FCM applications have emerged in industrial biotechnology, food and pharmaceutical quality control, routine monitoring of drinking water and wastewater systems, and microbial ecological research in soils and natural aquatic habitats. This review focuses on the information that can be gained from the analysis of bacteria in water, highlighting some of the main advantages, pitfalls and applications.
\end{abstract}

Keywords Bacteria · Flow cytometry · Fluorescence . Water $\cdot$ Single-cell analysis

\section{F. Hammes $\cdot$ T. Egli $(\square)$}

Eawag, Swiss Federal Institute of Aquatic

Science and Technology,

8600 Dübendorf, Switzerland

e-mail: egli@eawag.ch

T. Egli

Institute of Biogeochemistry and Pollutant Dynamics,

ETH Zürich,

8092 Zurich, Switzerland

\section{Introduction}

More than a century ago, Frankland (1896) aptly stated that the goal of every aquatic microbiologist is "...the discovery of the living, as distinguished from the dead and unorganized matter in the water" [1]. Indeed, the accurate and rapid detection of microbial cells, including their concentration, morphology, type, activity and physiological state, remains an ongoing challenge across a broad spectrum of research and application domains. This challenge includes questions as diverse as gaining quantitative information on specific microbial populations in natural surface water [2] to monitoring the quality of liquids used in food and pharmaceutical industries [3].

The initial discovery of single-cell microbes in 1676 by the Dutch cloth merchant and "amateur" scientist Antonie van Leeuwenhoek was made with a cultivation-independent approach, namely microscopy. It took another 200 years before bacterial counting in water became a routine process. Ironically, it was cultivation-based plating on semisolid nutrient media (so-called heterotrophic plate counts) that emerged and remained as the method of choice for enumeration of bacteria in aquatic samples during the last century $[1,4]$. The last three decades have witnessed a dramatic paradigm shift in the perception and understanding of indigenous microbial communities. Considerable technological advances, including the emergence of molecular microbiology, have illuminated a complex and abundant presence of microbial life in nearly every aquatic environment. These new approaches have highlighted an immense underestimation of bacteria detected with conventional plating methods compared to bacteria detected with cultivation-independent cytometric methods - a phenomenon that is classically referred to as "the great plate count anomaly" [5]. Cytometry is defined as the counting of cells, 
and in this broad description includes a host of exciting tools, including automated epifluorescence microscopy, solid-phase or laser scanning cytometry, Coulter counters and flow cytometry (FCM). These methods share many properties and several studies have compared the various cytometric techniques with one another [6-8]. The present review deals specifically with FCM and the data that can be gained with this technique.

Reduced to the essence, FCM is a technique for analysing individual particles by suspending them in a flow stream that passes through an excitation light source, typically a laser beam [9]. Interaction between the light beam and the particle causes specific scattering of light and excitation of fluorochromes; scattered light and emitted fluorescent light are then detected and measured with photomultipliers (Fig. 1). Light scattering is detected either at a low angle, commonly referred to forward scatter (FSC), or at a high angle (sideward scatter; SSC), whereas the fluorescence is detected at a high angle after selection with appropriate wavelength filters. Instruments with multiple lasers and/or detectors allow users to assess different fluorescence and scatter parameters simultaneously. A key feature of FCM hardware is that the suspended particles are passed individually through the light beam in single file in a process known as hydrodynamic focusing, thereby allowing analysis of a microbial community on a single-cell level. Thus, when combined with fluorescent cell-staining methods, FCM allows quantitative, multiparametric analysis of the detected particles, including their fluorescence intensity, the scattered light and an enumeration of particles. FCM differs notably from epifluorescence microscopy in that actual images of the bacteria are usually not produced; rather, digitalized data of the fluorescence or scattered light intensity characteristics of each particle are collected and presented as either single-parameter histograms or dualparameter dot plots (Fig. 1). This choice of the data presentation style is the prerogative of the FCM operator. In addition, most FCM software allows the operator to select specific areas of interest (e.g. separation of bacterial clusters from the background) in a process called "gating" (Fig. 2). Individual flow cytometers differ widely with respect to their light source (type and power) and detector configurations, and range from small affordable bench-top instruments to powerful high-throughput single-cell sorters
Fig. 1 The basic principles of flow cytometry (FCM) analysis, showing the interaction between a light source (laser beam) and a particle suspended in the flow stream, with resulting light scatter and fluorescence. The histogram and the dot plot data show two commercially available bead standards ( 2 and $3 \mu \mathrm{m})$ separated in this example by size (forward-scattered light; $F S C$ ) and green fluorescence intensity (FLI). Different types of gating ( $R N 1$ and $R l)$ are used by the operator to select clusters or regions of choice
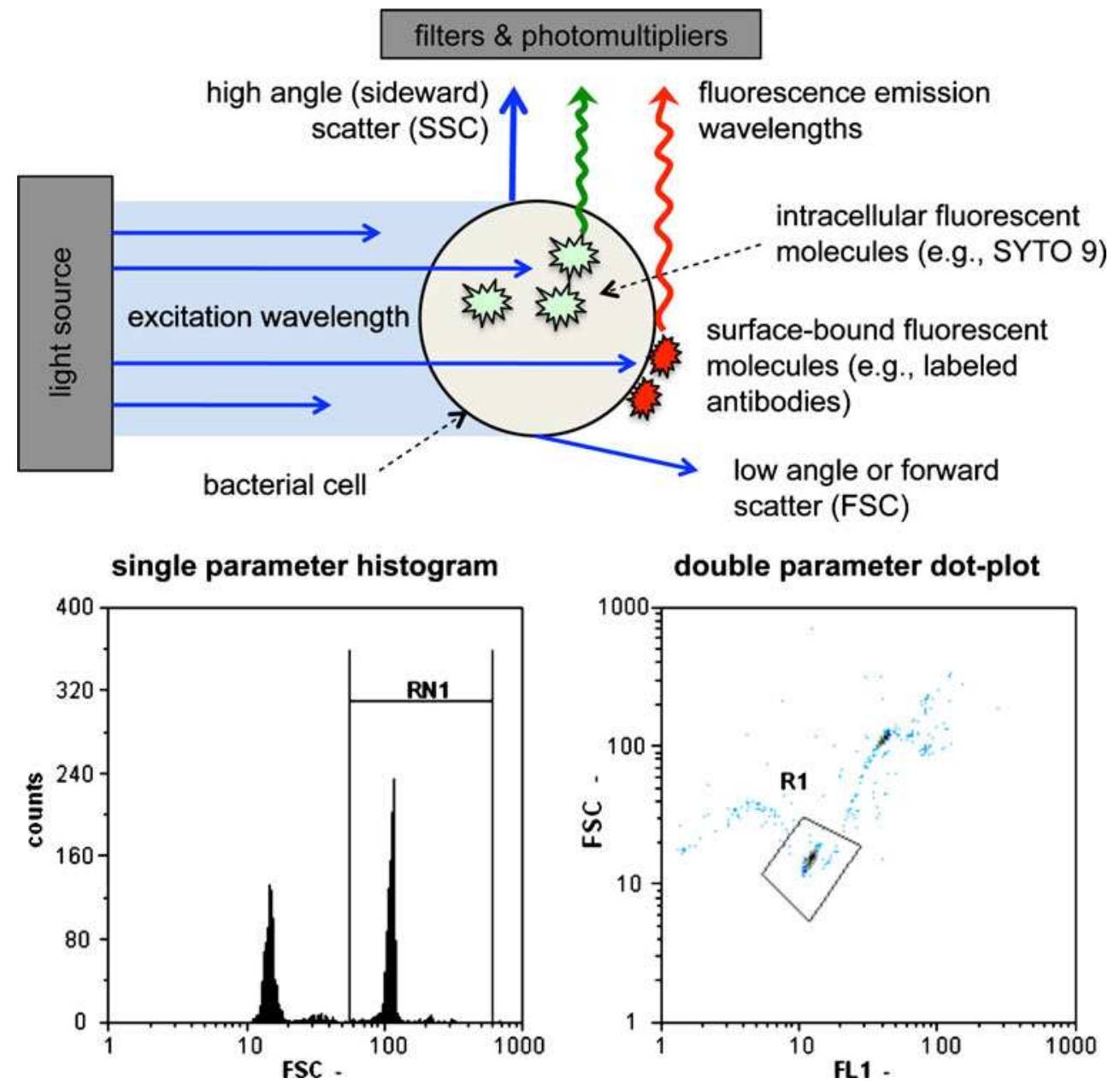
Fig. 2 Typical features of FCM data. A conceptual example of typical dot plot data combining any two parameters and giving rise to specific bacterial clusters, instrument noise and background signals inherent to the sample

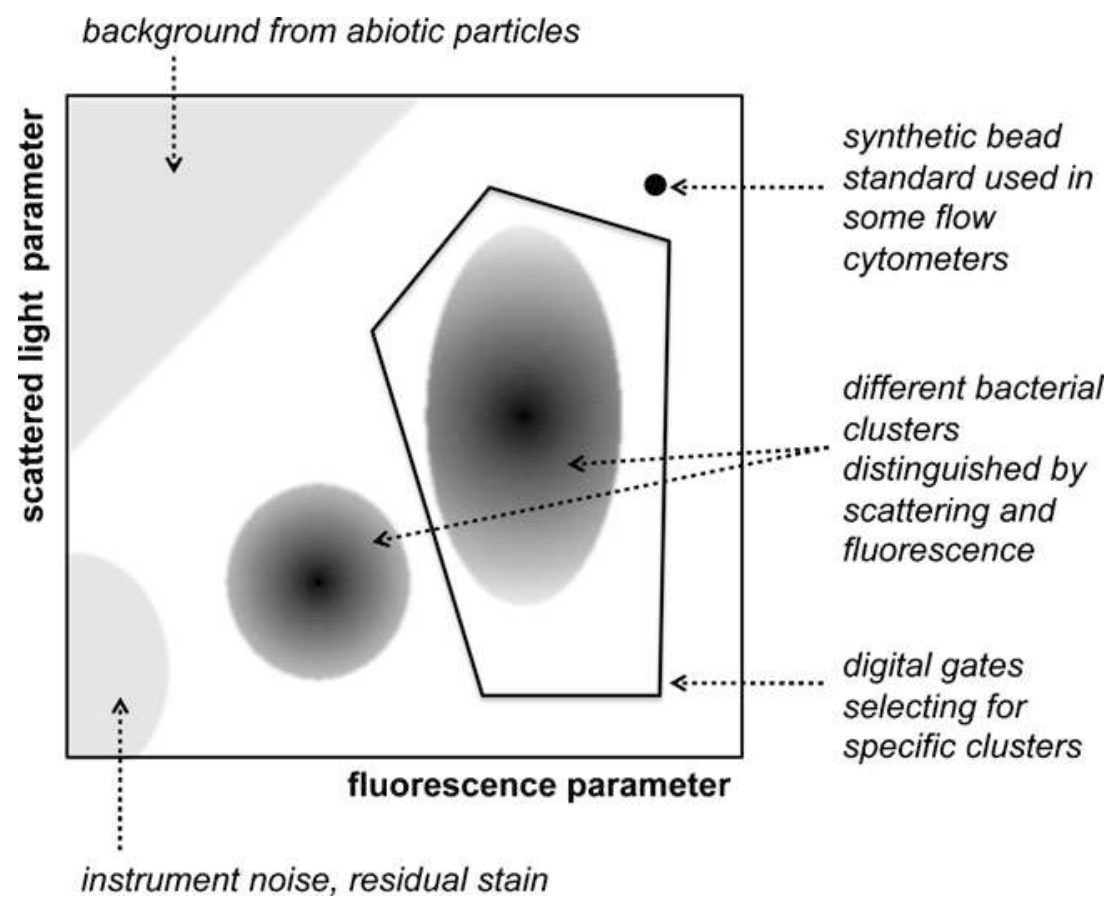

[9]. Established already for more than 30 years in medical research and routine diagnosis/analysis (e.g. blood cancers), the technique has witnessed a phenomenal rise of its use in the field of aquatic microbiology during the last two decades, with considerable and continual increases in the average number of publications per year. This can be attributed to three main facts: (1) specific technological developments (mainly for routine medical diagnostics) have transformed flow cytometers into easy-to-operate instruments available for standard laboratory research, (2) the continuous emergence of novel stains, fluorescent markers and related methods that are compatible with microorganisms and (3) improvement in hardware that allows detection of ever-smaller particles with low fluorescence intensity. This review deals exclusively with bacterial detection. However, it is noted that FCM is equally useful for the measurement of yeast cells [3], algae [10], protozoa [11] and viruses [12] in aquatic environments.

The main advantages of FCM are that analysis is fast (less than 3 min per sample), accurate (less than 5\% instrumentation error), sensitive (detection as low as 100 cells per millilitre) and compatible with a variety of staining and labelling methods providing broad information at the single-cell level. In addition, FCM instruments are fairly easy to handle with considerable automation potential. However, FCM also has notable limitations and pitfalls. FCM is a single-cell method and, therefore, is not ideal for complex macroparticle analysis (e.g. biofilms or activated sludge flocs). Although proper dispersion protocols allow visualization of such samples [13], the three-dimensional spatial aspect-often important for such samples-is completely lost. Similarly, samples with inorganic turbidity (e.g. soil or sediment extracts) often require special pretreatment (e.g. density centrifugation) before analysis can be done [14]. An interesting FCM problem is the relative ease with which an immense wealth of data can be generated. Although this might appear as only a positive point, it calls for standardization on multiple levels. Different brands of instruments give different results, as do variations in the water matrix, the type of target cells and the particular staining method [15]. Therefore, an absolute need exists for the correct reporting of FCM data, which would allow correct interpretation and evaluation of results. These issues are dealt with in detail elsewhere $[15,16]$.

This review examines the type of data that can be obtained with FCM, specifically the difference between working with pure cultures as opposed to indigenous microbial communities in "real aquatic samples", including some examples of interesting applications and future developments. For additional information, a general overview of FCM can be obtained from the seminal work of Shapiro [9], whereas three recent review papers addressed specifically the state-of-the-science applications of FCM in environmental microbiology and biotechnology $[3,17,18]$. The historical evolution of this field of research over the last three decades can be followed in earlier reviews [19-21]. An extensive list of useful stains for natural communities can be found in Gasol and del Giorgio's overview [22]. In addition, the Web site hosted by Purdue University (http://www.cyto.purdue.edu) offers interesting and updated information on many aspects related to FCM and microbiological analysis. 


\section{Information obtainable from FCM data}

An overview of the different types of information that can be obtained from FCM analysis of bacteria is given in Table 1 and Fig. 2. It should be noted that the combination of possible results shown in Table 1 is usually not obtained from a single analysis, but often requires individual methods and procedures that may be incompatible with one another and which require specific adaptation to unique samples. The purpose of this review is not to provide methods or protocols, but rather to highlight some of the well-known tools and the possible applications that can be explored with this technique.

\section{Absolute cell counts}

Absolute or total cell counting is one of the most straightforward and useful functions of FCM, with immediate applications in research, routine monitoring and quality control laboratories. In fact, the ability for fast, accurate, automated cell counting is one of the key features that renders FCM superior to comparative techniques such as epifluorescence microscopy. The challenge for the FCM operator is to be able to separate small bacterial cells from abiotic particles and background signals in a water sample. This is accomplished by staining the bacterial DNA (or other typical cell components) with a fluorescent dye such as SYBR Green I, SYTO 9 or 4',6-diamidino-2-phenylindole $[22,23]$. A first selection step is then triggering the selective bacterial parameter (e.g. green fluorescence in the case of SYBR Green I staining); thereby, non-fluorescent background particles would automatically be filtered out of the data set generated. The signals obtained are subsequently visualized either as single-parameter histogram data or as dual-parameter dot plot data (Figs. 1, 2 and 3). The advantage of the latter is that it allows the use of two parameters to discriminate between the bacterial signals and the background, either by the unique fluorescence characteristics of the stain bound to bacterial DNA or by specific characteristics of the cell size and shape (Fig. 2). Figure 3 shows possible cell counting strategies for a river water sample, stained with SYBR Green I. It is evident in this example that the bacterial clusters ( 1 and $\mathrm{c} 2$ ) and background signals $(\mathrm{a}, \mathrm{b})$ would overlap on singleparameter histogram data (e.g. FL1), which would render counting inaccurate. A common approach is to plot scatter data (FSC or SSC) against the fluorescence signals of the stains [23], thus utilizing the size/shape of the bacteria as a second selective factor. Alternatively, Hammes et al. [24, 25] have demonstrated that the combination of two fluorescence signals (e.g. green vs. red fluorescence) originating from the same dye can also be used (Fig. 3), and that it is in some situations the superior approach. For example, Fig. 4 shows a drinking water sample that was frozen and thawed before total cell concentration analysis. In this extreme example, small inorganic calcite crystals that are particularly abundant in the water interfere completely with the SSC signals (Fig. 4, plot B), but not with the bacterial fluorescence "fingerprint" (Fig. 4, plot A) in the sample.

Whichever approach is taken, it is essential that the operator strives to obtain optimal signal-to-noise ratios and cell clusters that are clearly separated from the background and which can be verified with control experiments. Cell counting is practically achieved by either volumetric counting hardware, present in some flow cytometers, or by the addition of a synthetic bead standard [22]. It is more than possible to achieve fast (less

Table 1 Flow cytometry data at a glance. A wealth of information pertaining to bacteria in water samples can be gained by using the correct combination of fluorescent stains, analysis techniques and pretreatment/post-treatment options

\begin{tabular}{llll}
\hline Data/information & Stains/label & Parameter & Example \\
\hline Total cell count & Nucleic acid (e.g. SYBR Green I) & Fluorescence & Lebaron et al. [23] \\
Cell viability/activity & Multiple stains with different targets & Fluorescence & Berney et al. [50] \\
Cell size/biovolume & NA & Mean FSC & Robertson and Button [26] \\
& NA & Mean SSC & Felip et al. [8] \\
Nucleic acid content & DNA (e.g. Hoechst) & Fluorescence & Müller [33] \\
& RNA (e.g. Pyronin Y) & Fluorescence & Shapiro [35] \\
Specific detection & Species (antibodies) & Fluorescence & Vital et al. [62] \\
& Groups (FISH probes) & Fluorescence & Sekar et al. [2] \\
Community "fingerprint" & Multiple stains with different targets & Specific clusters & Wang et al. [27] \\
Prefractionation & Microfiltration & Any & Wang et al. [41] \\
Prefractionation & Immunomagnetic separation & Specific detection & Füchslin et al. [61] \\
Cell sorting & Any of the above & Any & Czechowska et al. [17] \\
\hline
\end{tabular}

FSC forward scatter, SSC sideward scatter, NA not applicable, FISH fluorescent in situ hybridization 
than 3 min per sample), accurate (less than $5 \%$ standard error) and reliable counting results with cell concentrations as low as 100-200 cells per millilitre [25]. The subjectivity in the counting process is introduced by the operator's decision on what to include in or exclude from the counting process with electronic gating. Although a standard bead sample (Fig. 1) or bacterial pure culture might be easy to detect, a sample of natural water containing small and weakly fluorescent bacteria, as well as considerable background, poses a much greater challenge (Figs. 3, 4). Hence, the need for controls and comparisons with other counting methods, e.g. (fluorescence) microscopy and/or plating (for pure cultures), cannot be overemphasized.

\section{Cell size}

The cell size or biovolume of bacteria can be estimated from FCM scatter data, and this is particularly useful when analysing differences amongst indigenous microbial communities [26] or when analysing bacterial growth curves [27]. A conventional approach is to measure the forwardscattered light as an indicator of particle size [9], and this approach has been applied for bacterial measurements previously [26, 28, 29]. Specifically, Robertson et al. [29] reported resolution of mean cell sizes around $0.05 \mu \mathrm{m}^{3}$ for indigenous aquatic bacteria. However, several researchers have found FSC not sufficiently sensitive for measuring the changes in the size of small cells, and have rather opted for using sideward-scattered light (Fig. 3) [8, 27, 30]. It is probable that hardware configurations on different FCM instruments might affect the choice between using FSC or SSC data. However, it is essential that this use should be tested separately for individual instruments and these instruments should be calibrated separately, with emphasis on specifically using different bacterial cultures across the desired size range for establishing a calibration curve. A recent paper by Foladori et al. [31] described the use of silica microspheres with a refractive index similar to bacterial cells for easy calibration of FCM scatter signals and biovolume. Mean scatter measurements used for cell size determination should, however, be seen as estimative values rather than direct measurements. As seen in Figs. 3 and 4, bacterial clusters are broad (compared with beads, Fig. 1) and the geometrical mean SSC (or FSC) value of these clusters represents at best an estimation of the average biovolume of the sample. Alternative approaches for size measurements are to relate the fluorescence intensity of specific stains in the cells (e.g. the DNA content) to the cell size [22], although particular care should be taken with the influence of cell physiological state (e.g. the presence multiple DNA copies in single cells [32]) on such an approach.

\section{DNA and RNA content of bacterial cells}

The nucleic acid content of bacterial cells can be estimated from the mean fluorescence intensity resulting from nucleic acid binding dyes, and this is approach is typically used to distinguish different populations in natural aquatic environments $[26,30]$ or subpopulations with different chromosome numbers in pure cultures [32,33]. Several general dyes that are used for total cell counting bind to both DNA and RNA. Although dyes such as Ribogreen and SYBR Green II have been suggested to bind preferentially to RNA, they were found to be insufficient to discriminate between active and inactive cells in natural environments [34]. For separate measurements of DNA and/or RNA, respectively, it is essential to use fluorescent dyes, which bind exclusively to the designated target, or which fluoresce at different wavelengths for each target molecule. Shapiro [35] provided one of the earliest examples of DNA/RNA staining for FCM, using Hoechst 33342 for DNA content and Pyronin Y for measuring the RNA content of intact cells. Other DNAbinding dyes include Picogreen and 4',6-diamidino-2-phe-
Fig. 3 Indigenous river water bacteria stained with SYBR Green I and plotted as a green fluorescence versus red fluorescence (FL1/FL3) and $\mathbf{b}$ green fluorescence versus size (FL1/ $\mathrm{SSC})$. The two main bacterial clusters $(c 1$ and $c 2)$ are clearly discernible, but abiotic particles in the water $(b)$ and instrument noise $(a)$ can potentially interfere with the measurements. SSC sideward scatter
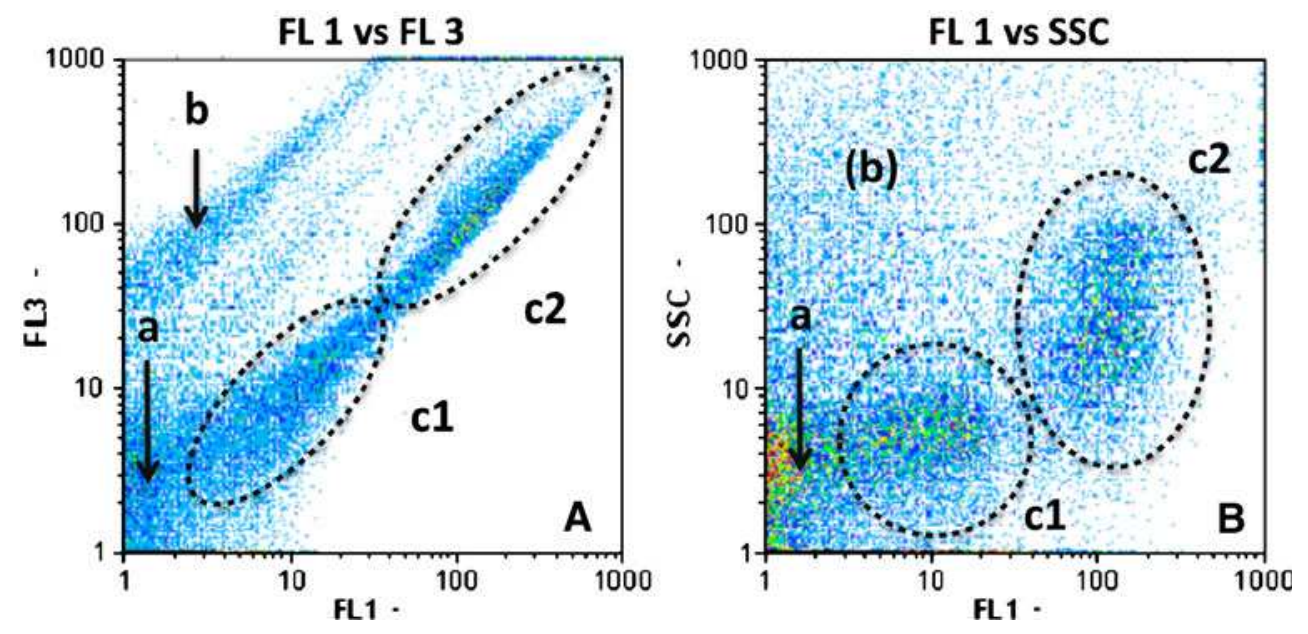
Fig. 4 Analysis of nonchlorinated tap water bacteria stained with SYBR Green I after freezing and thawing. a The green fluorescence versus red fluorescence (FL1/FL3) dot plot distinguishes between bacteria (R1) and abiotic particles (R2), but $\mathbf{b}$ the dot plot of green fluorescence versus size (FL1/ SSC) does not

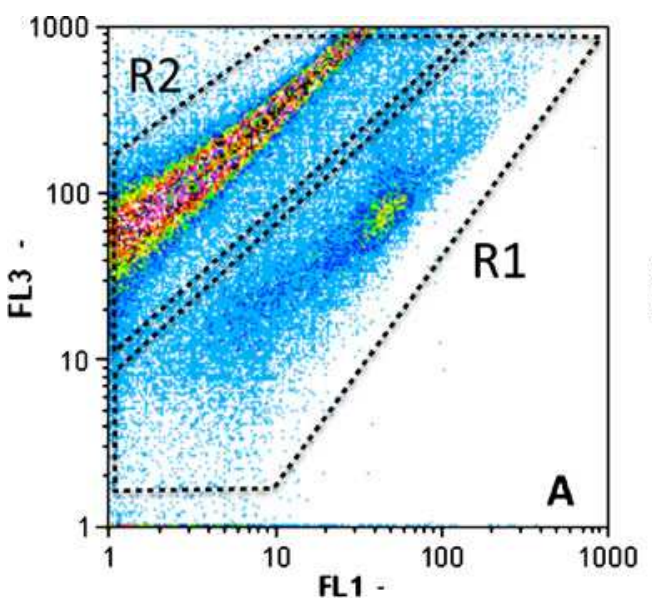

nylindole, both binding specifically double-stranded DNA $[26,33]$, whereas acridine orange binds to both DNA and RNA but fluoresces at different wavelengths. Notably the specific detection of DNA is often done with high-poweroutput lasers (more than $300 \mathrm{~mW}$ [32]), which might pose problems when this approach is transferred to bench-top flow cytometers with lower-power lasers (e.g. 10-20 mW). The RNA content of bacterial cells can also be measured with fluorescent in situ hybridization (FISH) probes [36]. Although this method can be useful for pure cultures, the heterogeneity found in indigenous microbial communities might render correct interpretation difficult.

The total nucleic acid content of bacteria from indigenous aquatic communities has been the source of one of the most interesting and somewhat controversial phenomena of FCM, namely the ubiquitous presence of high nucleic acid (HNA) and low nucleic acid (LNA) content bacteria. The terms HNA and LNA refer to two clusters distinguished primarily by differences in fluorescence intensity resulting from common nucleic acid stains such as SYBR Green I, SYBR Green II, SYTO 9 and SYTO 13 [27, 37, 38]. These clusters were initially termed "group I cells" and "group II cells" [39] and were then renamed "low-DNA bacteria" and "high-DNA bacteria" [37], and both clusters are prevalent in nearly all aquatic samples, including marine, brackish and freshwater environments [27, 30, 38]. Ever since the first description, this differentiation has been the focus of ongoing debate. No other comparative method (e.g. quantitative fluorescence microscopy) differentiates so clearly between only two groups of indigenous bacteria in natural environments. However, limiting the analysis of indigenous communities to only two broad groups with FCM is highly subjective, probably instrument specific and certainly provides only a limited description of the microbial communities' properties, as multiple clusters are often observed in FCM dot plots [40, 41]. Moreover, a comparison of typical HNA and LNA data sets presented in the current literature demonstrates that there is also little consensus amongst researchers about which parameters exactly define these groups (Fig. 5). One of the central issues in the HNA/LNA debate is the question of viability and activity [42]. Lebaron et al. [38, 43] have argued that LNA bacteria are not active and that this differentiation can be used as a convenient viability/activity indicator for bacterial cells from aquatic environments. This idea was applied in practice by Phe et al. [44], who suggested that a shift from HNA to LNA cells during chlorination (after SYBR Green II staining) is demonstrative of the disinfection process, based on the argument that LNA bacteria are not viable. However, these results are countered to some extent by work done in the authors' group, which included isolation and cultivation of LNA bacteria, demonstrating that representatives of this group are perfectly viable and active in low nutrient environments [27]. Indeed, other researchers have also reported activity and viability detected in the LNA group $[30,45]$. An interesting recent study has suggested that the shift between HNA and LNA in Vibrio parahaemolyticus (normally HNA cells) is indicative of the formation of viable-but-not-cultivable (VBNC) cells [46]. It is evident that additional research on this phenomenon may still yield several interesting results and that this phenomenon probably cannot be solved by FCM as a technique alone.

\section{Bacterial viability analysis}

Cultivation-independent viability analysis on the single cell level is one of the finest uses of FCM. The outright advantage is that it allows rapid and quantitative viability analysis of uncultivable bacteria [47], or cultivable bacteria that have entered an uncultivable (so-called VBNC) state [46, 48]. In addition, the use of multiple stains with different target sites allows the researcher to determine a sequence of damage to different cellular compartments [4951], or to pinpoint the extent of damage on a specific target site [44]. In this manner, considerably more information is gained on the mode of cell damage and the function of bactericidal agents. Moreover, FCM analysis often shows 
Fig. 5 Four examples of high nucleic acid (HNA) and low nucleic acid $(L N A)$ differentiation by four different research groups, all based on nucleic acid staining and analysis of sideward scatter and green fluorescence: a microbial community of river water samples [38]; b bacterioplankton in a mesotrophic lake stained with SYBR Green I [40]; c marine bacteria stained with SYBR Green I [42]; d indigenous river water bacterial community stained with SYBR Green I (authors' group). VHNA very high nucleic acid

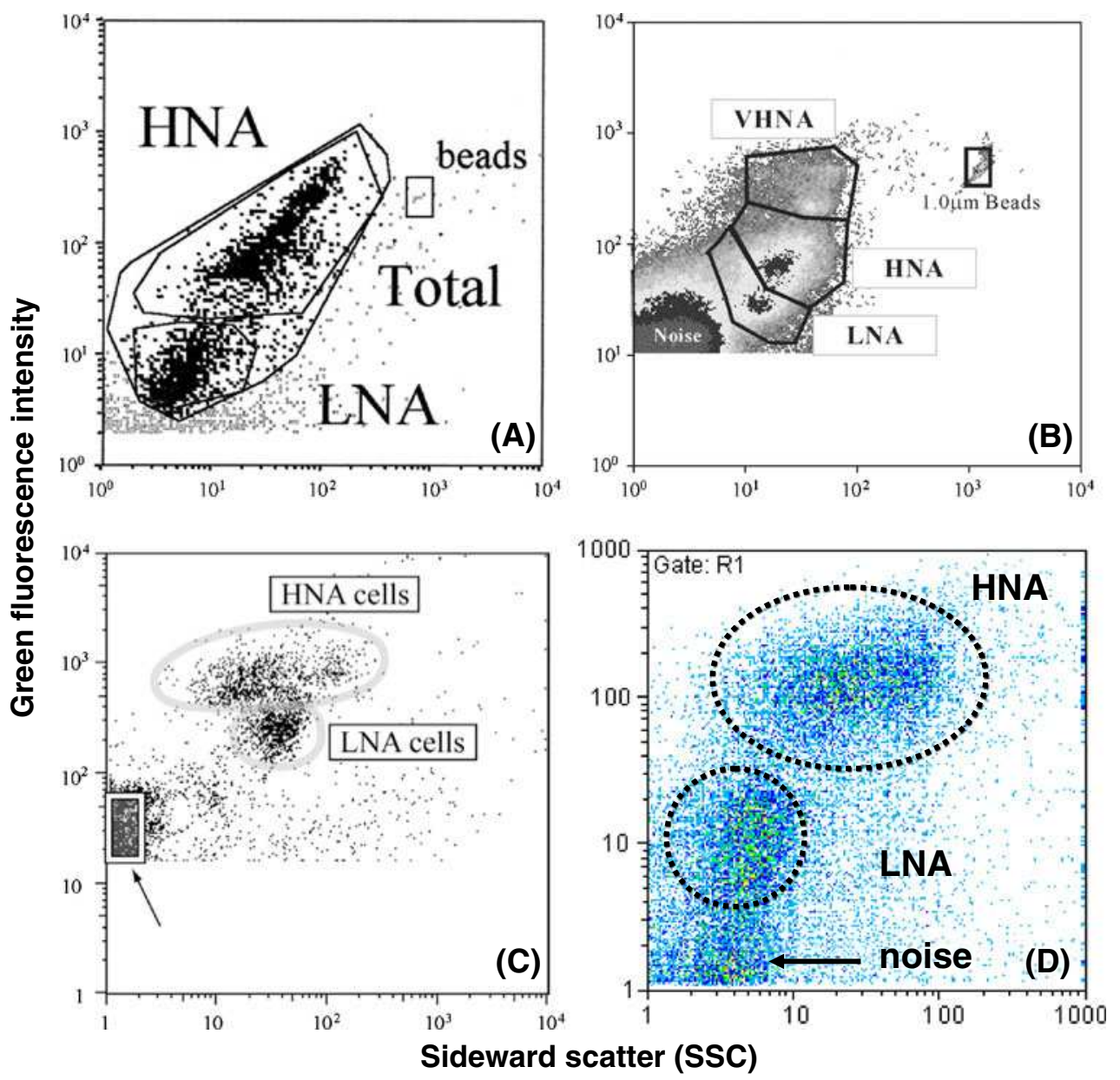

intermediate states, or so-called injured cells, during viability analysis, thus serving as a more comprehensive descriptor of cell damage than merely "viable or not" [52, 53]. However, these obvious advantages come with a warning label attached: the tendency exists to view viability-staining methods as off-the-shelf and from-themanuscript applications, with the danger of erroneous applications and interpretations. Different environments, organisms and bactericidal agents require rigorous selection, testing, calibration and standardization of the viability assays and protocols to be used, and some examples in this respect will be highlighted below. Additionally, it is imperative to combine FCM viability data with other independent parameters. Where applicable, direct cultivability [50], ATP analysis [25, 47, 50] and labelled substrate incorporation [30] are all interesting examples that can be used to validate and support FCM data.

There exist numerous fluorescent stains for viability analysis, and the reader is referred to a selection of papers for comprehensive schematic and tabular information on a variety of these stains and staining methods [3, 22, 50, 54]. Of these, some of the best-known examples are stains assessing membrane integrity (e.g. propidium iodide), membrane potential [e.g. bis(1,3-dibarbituric acid)trimethine oxanol], efflux pump functioning (e.g. ethidium bromide), esterase activity (e.g. carboxyfluorescein diacetate), bacterial respiration (e.g. 5-cyano-2,3-ditolyl tetrazolium chloride) and fluorescent glucose-analogue incorporation [e.g. 2-( $N-(7-$ nitrobenz-2-oxa-1,3-diazol-4-yl)amino)-2-deoxyglucose]. What is of critical importance is to appreciate the diversity and complexity of microbial life, and to understand that nearly no stain would function equally for all organisms and in all environments. For example, propidium iodide functions exceptionally well to assess irreversible membrane damage to pure cultures of Escherichia coli, Salmonella typhimurium and Shigella flexneri cells exposed to sunlight [50, 51], but has been shown to produce completely erroneous results with a growing Sphingomonas culture [55]. In fact, several researchers have commented previously that specific care should be taken with optimizing the correct concentration of propidium iodide to avoid false-positive interpretations [53]. Similarly, esterase activity stains are often seen as good activity indicators, but since these dyes are dependant on passive transport into cells, followed by a reaction with esterases (enzymes), these stains would react equally well in dead as well as living cells [56].

A common sense approach with viability staining is to select stains specifically for the intended purpose. For 
example, chlorination (and other oxidizing/reactive chemical agents) oxidizes initially bacterial membranes, thus causing physical damage to the cell membrane. Therefore, a dye targeting membrane integrity (e.g. propidium iodide) would suffice to characterize this specific form of damage clearly (Fig. 6) [53]. However, UV-C disinfection, which damages bacterial DNA, would not be detected at all with this approach [56]. The work with cultivation-independent viability analysis has created many interesting questions and options regarding the definition of viability and the parameters with which this can be assessed. Although currently no single, definitive viability stain exists, it is evident that this approach has the potential to describe, characterize and understand cellular behaviour in stressful environments.

Detection of specific bacterial groups or species

Specific detection of selected bacteria was one of the earliest applications envisioned for FCM [57, 58], and can be used for quality control (pathogen screening) or ecological research [2]. Group- or organism-specific detection requires two basic elements, namely (1) a probe or marker molecule of some sort, which is fluorescently labelled and binds exclusively to the target and distinguishes the target cell from the background, including non-target indigenous bacteria, and (2) an adequate concentration of the target cells to detect them in a quantitative and accurate manner.

\section{Marker molecules}

There are two basic types of marker molecules, namely monoclonal or polyclonal antibodies and conventional FISH probes for ribosomal RNA, both of which require labelling with a fluorochrome such as fluorescein isothiocyanate (FITC), quantum dots or similar [59-61]. Surface antibodies have the advantage of being non-invasive, thus requiring no serious pretreatment processes, and can therefore be used in combination with conventional total cell count or viability dyes $[62,63]$. The disadvantage of antibodies is that they can be difficult to obtain and that the binding-properties can vary; also they tend to be organismspecific or often even serotype-specific. The latter can be an advantage, but then the method cannot be applied to larger groups of interesting organisms. Also, the number and even the presence of an antibody epitope on the target cell surface can sometimes vary with cultivation conditions. FISH probes can be group-specific or species-specific, and have the advantage that a wide range of such probes with proven abilities (from peer-reviewed literature) is available. The disadvantages of FISH probes are that they require aggressive pretreatment processes that were not originally designed with FCM compatibility in mind [64]. In addition, indigenous bacteria from oligotrophic aquatic communities are often small with low specific activity (and therefore low ribosomal RNA concentrations); hence, it can be difficult to detect these accurately. A possible solution lies in the use of alternative probes such as DNA molecular beacons [65], or the use of much stronger fluorescent markers such as quantum dots $[59,66]$.

\section{Concentration of cells}

A statistically reliable detection result requires a concentration exceeding 100 cells per millilitre with a target-tobackground cell ratio in excess of $1 \%$. This poses a considerable challenge for pathogen detection in natural aquatic environments, where the concentration of the target cells is typically low. For example, non-chlorinated drinking water typically contains about $10^{5}$ cells per millilitre of indigenous bacteria [25], but legislation requires E. coli counts to be at least $7 \log$ units lower (less than one cell per $100 \mathrm{~mL}$ ). Therefore, preconcentration of the target cells is required. In the last few years, immunomagnetic separation (IMS), using various magnetic beads or paramagnetic particles coated with cell-surface antibodies for specific
Fig. 6 Basic viability staining. Membrane damage to Escherichia coli $\mathrm{K} 12$ before (left plot) and after (right plot) exposure to chlorine dioxide is clearly detectable after staining with SYBR Green I and propidium iodide. Data are shown as dot plots of green fluorescence $(520 \mathrm{~nm})$ versus red fluorescence $(630 \mathrm{~nm})$
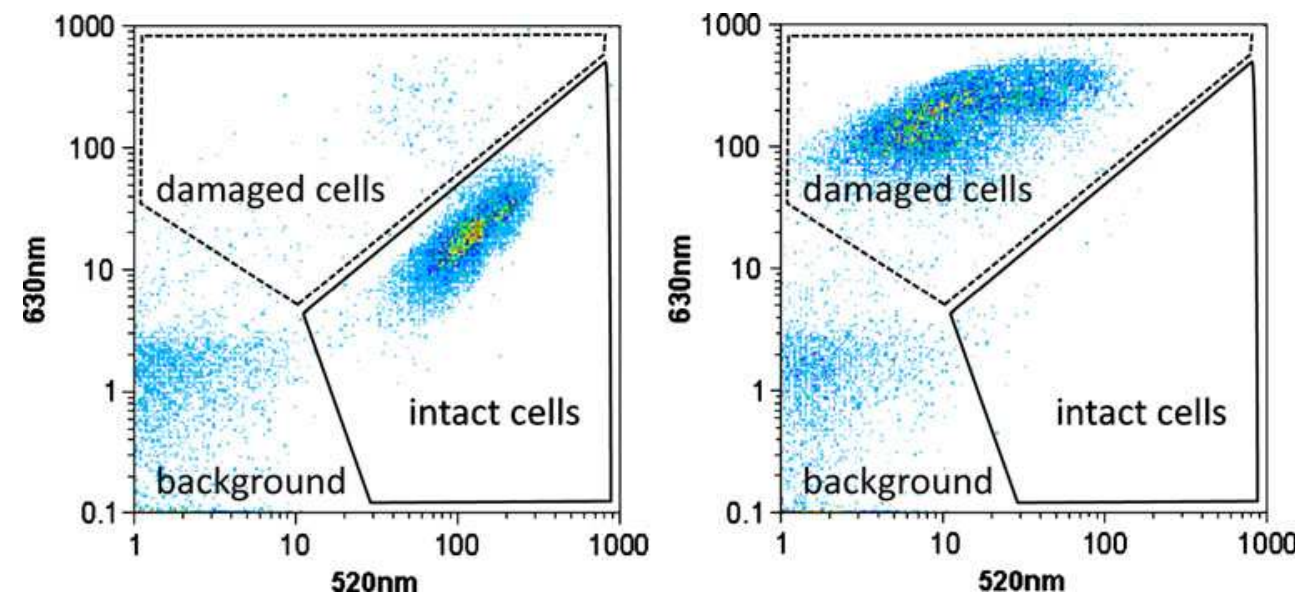
pathogens, has become an established technique. After incubation of a sample containing target cells with antibody-coated magnetobeads, the magnetobead-target cell complex can be collected with a strong magnet, which, combined with washing steps, results in a selective enrichment and concentration of the target cells. The technique was first applied as an enrichment/purification step for subsequent PCR analysis [67, 68] or solid-phase scanning cytometry [69], but has been used recently also in FCM applications (see later). IMS combined with conventional filtration and washing procedures has much potential for routine fast pathogen screening with FCM.

Preanalysis fractionation and postanalysis cell sorting

The IMS described in the previous section is a typical example of preanalysis fractionation to improved FCM detection. FCM of bacteria usually does not suffice without at least a basic form of pretreatment such as staining. However, a considerably broader application of sample fractionation prior to analysis can yield additional information (or reduce the problem of unspecific signals, excessive background, etc.), specifically where indigenous communities are concerned. For example, size-exclusion microfiltration has been used in at least two studies to separate indigenous communities on the basis of cell size (or filterability) [30, 41]. An example of this approach is shown in Fig. 7, where a freshwater sample (river water) is fractionated with $0.45-\mu \mathrm{m}$ microfiltration prior to straightforward FCM analysis (SYBR Green I staining). It is conceivable that significant future advantages can be expected in this domain.

Specifically designed flow cytometers are capable of sorting selected populations in a precise, accurate and fast manner (known commonly as fluorescence-activated cell sorting, FACS). This offers the researcher nearly unlimited possibilities to investigate clusters of interest further using, for example, regrowth, microscopy and molecular analyses $[2,27,70,71]$. Undoubtedly, this is an application of FCM that will still see considerable future advances. For indigenous bacteria, there is a concrete need for the development of stains that are non-aggressive or nonlethal. This would allow separation and cultivation methods without the problems associated with them otherwise [27].

\section{FCM clusters and gating strategies}

The HNA/LNA examples shown earlier (Figs. 3, 7) do not represent the entire possible range of FCM data. FCM analysis of indigenous communities often generates multiple clusters of bacteria and background. The emphasis is on the operator to distinguish background from bacteria, and different bacterial clusters from each other. Unfortunately, this can be one of the most subjective aspects of FCM, and even though cluster analysis software was described long ago [72, 73], most users still rely on manual, operatordefined gating. Although expert research groups have undoubtedly well-designed gating strategies based on experience and sufficient and correct controls, this gating can also be misleading and confusing to the untrained eye. For example, Wang et al. [41] described up to five different clusters in a sample of bottled groundwater, and Günther et al. [74] recognized at least 17 prominent clusters in a sample of wastewater (Fig. 8). Neither of these studies described any specific statistically based gating strategy, but visual inspection and personal experience seem to be the criteria applied. Considering that FCM is based on the detection of a large number of events, existing specific software can be applied for cluster analysis [73]. Even though this might not immediately replace the strategy of trained researchers, it may aid the correct (gating) clustering and improve the understanding and conviction of non-FCM researchers dealing with such data. Objective and automated cluster analysis also has the potential to be more than merely a
Fig. 7 Fractionation of an indigenous river water microbial community a with $0.45-\mu \mathrm{m}$ filtration, followed by staining (SYBR Green I) and FCM analysis. The percentage of $0.45-\mu \mathrm{m}$-filterable bacteria from the so-called HNA and LNA clusters is indicated (b)
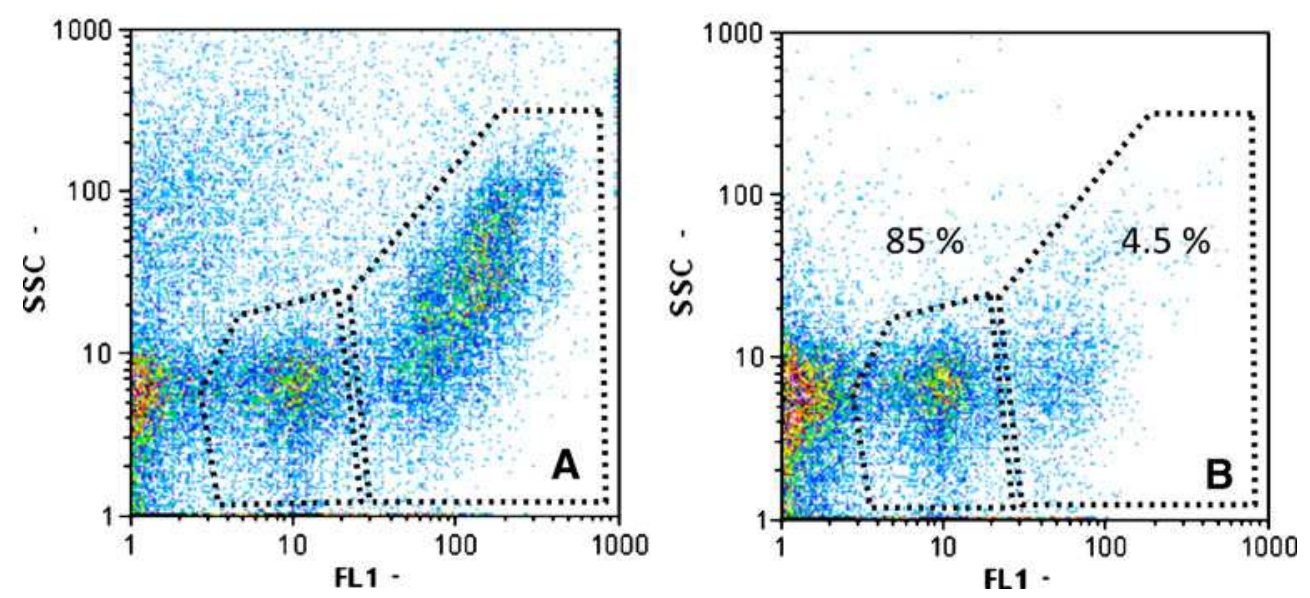
Fig. 8 Two examples of FCM gating and clustering strategies: a 15 bacterial clusters in wastewater [74]; b five bacterial clusters in bottled groundwater [41]
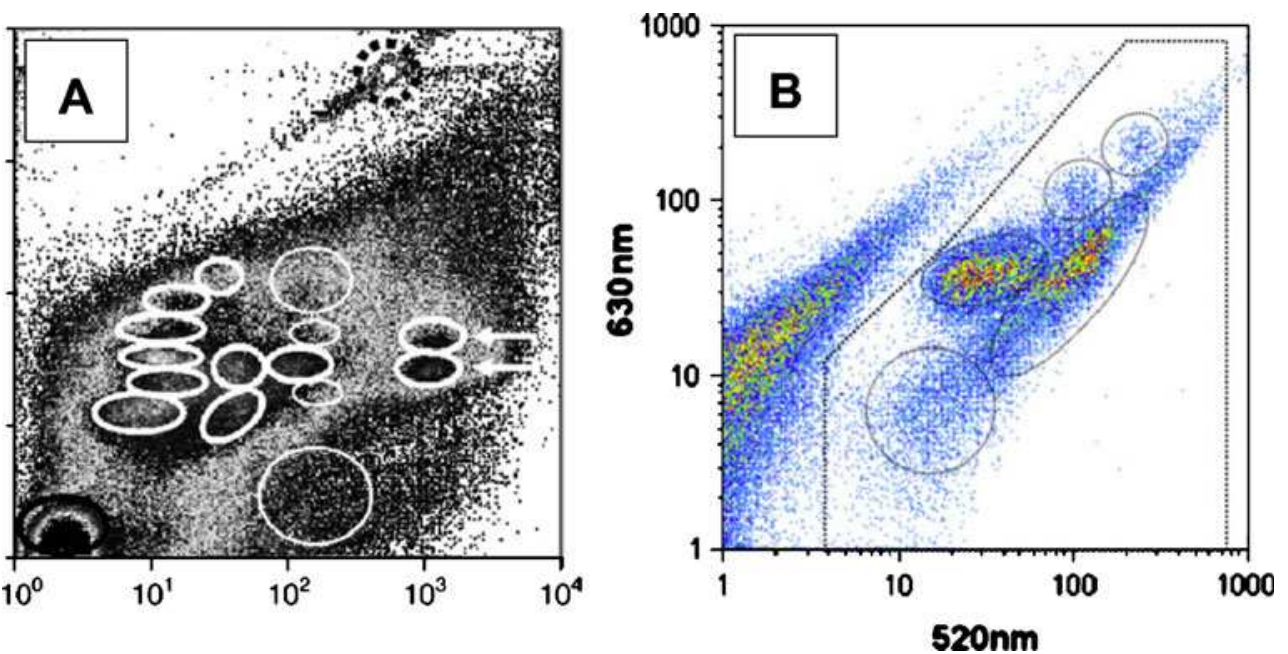

standardization of data analysis procedures. Multiparametric FCM clusters can be used as "fingerprints" during routine monitoring of bioreactors with pure cultures as well as indigenous communities (e.g. wastewater or drinking water treatment). For example, automated detection of deviations in parameters such as fluorescence intensity and cell size and/or cell concentrations can act as early warning systems, even if the cause is unknown.

\section{Additional parameters}

Parameters that were not discussed in the previous sections but that can be useful for FCM measurements include cell shape, intracellular $\mathrm{pH}$ measurements, fluorescence Gram staining, autofluorescence, expression of fluorescent proteins (e.g. green fluorescent protein, yellow fluorescent protein), total cellular protein measurements and cellular lipid measurements [22, 75]. Moreover, sample preservation (fixation) is a key point that can influence FCM measurements. Several fixation strategies were examined and discussed in detail by Günther et al. [74].

\section{Applications of FCM data}

The examples listed in the following sections are by far not exhaustive and only demonstrate some FCM applications that provide an improvement on state-of-the-art methods in the respective fields. The reader is referred to recent reviews [3, 18] where extensive summaries of FCM applications are presented.

Routine monitoring of water treatment systems and industrial bioprocesses

Routine monitoring of drinking water treatment and distribution systems worldwide is still done with conven- tional heterotrophic plate counts [76] (even though this method requires several days for finalization of results and detects only a minute fraction of the indigenous bacteria in the water [5, 25]). The speed of FCM measurements makes this a valuable method that would allow for rapid response in the case of abnormal results. Although FCM total cell counting is the most straightforward method for routine analysis of drinking water [25, 77], viability methods are particularly useful when disinfectants are present in the water [47, 78]. In addition, cell size and nucleic acid content have been used previously to describe microbial growth in bottled groundwater [41]. The same methods that are successful for large-scale drinking water treatment systems would suffice for monitoring wastewater treatment systems [79] as well as decentralized treatments such as hospital filtration systems or process water production facilities. It is probable that increased requirements for post-treatment of wastewater effluents would see an increased demand for rapid, routine monitoring methods. The main challenge with analysis of water treatment systems is that the FCM methods should function with indigenous microbial communities, the composition of which is usually unknown. It is conceivable that this field will see the development of chip-sized, purpose-specific FCM instruments with automated data processing to allow eventual online/in-line processing and real routine monitoring [10, 64, 80].

Monitoring of industrial bioprocesses such as beer/wine production, quality control in diary processes and highdensity fed-batch fermentations is one of the betterestablished FCM applications [3, 52, 75, 81]. The FCM applications can range from simple total cell counts to complex viability analysis. For example, Hewitt et al. [52] demonstrated the development of subpopulations with different physiological states during the course of a fedbatch fermentation, and emphasized the value of such data for modelling fed-batch processes. In a similar application, 
Looser et al. [82] showed the sensitivity of ethidium bromide for monitoring $E$. coli cell damage during overexpression of a foreign membrane protein, whereas Lahtinen et al. [48] used FCM to analyse the occurrence of so-called VBNC cells in probiotic cultures, highlighting that better product regulation in the probiotic industry might be achieved with this approach. As with the water treatment systems, the expected future development for bioprocess monitoring involves the establishment of small, automated, online, purpose-designed instruments [75], and considerable advances have already been made in this field [83].

\section{Understanding disinfection and bactericidal processes}

Some disinfection processes such as membrane ultrafiltration are straightforward and can be analysed rapidly with presence/absence total cell count. However, as discussed already, bacterial viability, activity and death are complicated concepts that are best illuminated with multiple analysis tools [84]. For example, Novo et al. [49] tested the effects of five well-known antibiotics on the membrane permeability and membrane potential of two bacterial pure cultures (Staphylococcus aureus and Micrococcus luteus) and were able to clearly demonstrate distinct differences in the bactericidal mode of the antibiotics on the two cultures. Similarly, Suller and Lloyd [84] analysed three pure cultures and three antibiotics with a variety of viability stains, and reported differences between the stains and results obtained from cultivation-based plate counts. Both studies concluded correctly that analysis of a single parameter would not suffice to characterize the sensitivities of all bacterial species to all antimicrobial agents. This notion was further underscored in a study of bacterial disinfection with sunlight, the so-called SODIS process. Damage to bacterial cells is caused primarily by the UV-A part of sunlight. Using an array of FCM stains combined with separate ATP analysis and cultivation-based methods, Berney et al. [50] demonstrated that cell damage in E. coli occurred in a particular order upon exposure to sunlight: the ATP concentration decreased first, accompanied by a cessation of efflux pump activity (stained with ethidium bromide). This was followed by a decrease in membrane potential [bis(1,3-dibarbituric acid)trimethine oxanol staining] and glucose uptake rate [2-( $N$-(7-nitrobenz-2-oxa-1,3diazol-4-yl)amino)-2-deoxyglucose labelling], which both occurred at the same time as irreversible loss of cultivability. Finally, the cell membranes became permeable (propidium iodide staining). Also in Salmonella and Shigella strains, although they proved to be more resistant to sunlight, the sequence of activity loss occurring was similar, pointing to a common mechanism of cell injury and dying process [51].
Analysis of communities in natural surface water

The combination of FISH and FCM for the analysis of subgroups in indigenous microbial populations was pioneered by the group of Amann [2, 85]. However, Gerdts and Luedke [64] pinpointed one of the key issues which has often limited the application of this method to natural aquatic environments, namely the low ribosome content of small, slow-growing bacteria. One approach is to use the catalysed reporter deposition FISH method that enhances the fluorescence signals [2], although questions remain about the cell loss incurred during the FISH protocol and the resulting impact on quantitative result. Gerdts and Luedke [64] described an interesting approach where a chip-based flow cytometer is used for detection of FISHstained cells, with the primary advantage that the flow rate in these systems is slowed down considerably so as to prolong the duration of individual particles in the laser beam. As a result, better discrimination between background and targeted fluorescence signals is obtained.

\section{Rapid pathogen screening}

The FCM detection of immunolabelled Legionella in water samples of cooling towers was reported in the 1980s [86, 87]; however, the method was not very sensitive and the early stage of the technique allowed only the detection of concentrations of Legionella in the range from $10^{4}$ to $10^{6}$ cells per millilitre. Immunocapture and immunolabelling methods for the detection of many other pathogens followed, including Campylobacter spp. [13], E. coli O157 [58], mycobacteria [60], Salmonella spp. [88], Listeria spp. [67, 89], Cryptosporidium [90] and Giardia (oo)cysts [91]. Whereas earlier methods used relatively large beads for immunocapturing $(1-5 \mu \mathrm{m})$, it has now become obvious that more efficient capturing is achieved with much smaller beads $(20-50 \mathrm{~nm})$. Recent work has shown that cells immunocaptured with small magnetic beads can be isolated with a high recovery of $95 \%$ or more, even from complex matrices such as milk, apple juice and manure, as followed by direct enumeration in the flow cytometer [89, 90]. In our own laboratory we have developed a cultivation-independent, quantitative and fast detection method for Legionella pneumophila in water samples [62]. The method consists of four steps, starting with a membrane filtration for collection of all cells from the sample, followed by a staining with FITC-labelled surface antibodies, then immunomagnetic capturing with anti-FITC immunomagnetobeads, and subsequent FCM detection. The method allows screening for Legionella pneumophila within $3 \mathrm{~h}$ with a detection limit of 500 cells per litre in tap water. Although the method is already being applied in the food industry and medicine, the detection of 
pathogens in drinking water is still in its infancy; here the low concentration of target organisms requires additional concentration steps before immunocapturing and immunodetection can be achieved.

\section{Conclusions: an exciting future of cytometry}

After about three decades of successful research coupled with continual technological developments, FCM applications have reached an important crossroad. On the one hand, development will drive exciting technological innovations e.g. small, multiparameter instruments, coupled with singlecell sorting and postanalysis methods. Whereas cell sorting is already a well-established technique, automated FCM is expected to see considerable evolution in the foreseeable future. Online FCM instruments are already a reality in some applications, such as bioreactor monitoring and limnological applications [10, 83]. Coupled with online data processing, this has a real potential for online monitoring of drinking water, wastewater and other industrial processes. On the other hand, there is a need for the basic FCM methods to become established as standard methods with broad acceptance in the scientific community, and the establishment of simple instrumentation for common use in research laboratories and companies. The use of multiple fluorochromes in combination with bacteria is still limited and nearly no papers have described more than two labels coupled to bacterial cells. Czechowska et al. [17] opined that the small cell size of bacteria might be an insurmountable physical restriction on the use of multiple dyes. However, it is conceivable that additional lasers and the use of fluorochromes such as quantum dots with narrow and well-defined emission spectra might provide opportunities for additional fluorescence labelling of cells [60]. As with all rapid-evolving methods, there is a definite need to safeguard against hastily produced/ interpreted FCM data. Standardized methods, rigorous controls and continual comparisons with existing methods should be the checks and balances that accompany the exciting and innovative exploration of this field.

\section{References}

1. Frankland P (1896) Nature 54:52

2. Sekar R, Fuchs BM, Amann R, Pernthaler J (2004) Appl Environ Microbiol 70:6210-6219

3. Diaz M, Herrero M, Garcia LA, Quiros C (2010) Biochem Eng J 48:385-407

4. Koch R (1883) In: Ärztliches Vereinsblatt für Deutschland, 1883, Nr. 137. Vogel, Leipzig

5. Staley JT, Konopka A (1985) Annu Rev Microbiol 39:321-346

6. Lemarchand K, Parthuisot N, Catala P, Lebaron P (2001) Aquat Microb Ecol 25:301-309
7. Lisle JT, Hamilton MA, Willse AR, McFeters GA (2004) Appl Environ Microbiol 70:5343-5348

8. Felip M, Andreatta S, Sommaruga R, Straskrábová V, Catalan J (2007) Appl Environ Microbiol 73:4508-4514

9. Shapiro HM (2003) Practical flow cytometry, 4th edn. Wiley-Liss, New York

10. Dubelaar GBJ, Gerritzen PL (2000) Sci Mar 64:255-265

11. Vesey G, Hutton P, Champion A, Ashbolt N, Williams KL, Warton A, Veal D (1994) Cytometry 16:1-6

12. Brussaard CP, Marie D, Bratbak G (2000) J Virol Methods 85:175-182

13. Waller DF, Ogata SA (2000) Appl Environ Microbiol 66:4115-4118

14. Christensen H, Bakken LR, Olsen RA (1993) FEMS Microbiol Ecol 102:129-140

15. Nebe-von-Caron G (2009) Cytometry Part A 75:86-89

16. Lee JA, Spidlen J, Boyce K, Cai J, Crosbie N, Dalphin M, Furlong J, Gasparetto M, Goldberg M, Goralczyk EM, Hyun B, Jansen K, Kollmann T, Kong M, Leif R, McWeeney S, Moloshok TD, Moore W, Nolan G, Nolan J, Nikolich-Zugich J, Parrish D, Purcell B, Qian Y, Selvaraj B, Smith C, Tchuvatkina O, Wertheimer A, Wilkinson P, Wilson C, Wood J, Zigon R, Scheuermann RH, Brinkman RR (2008) Cytometry Part A 73:926-930

17. Czechowska K, Johnson DR, van der Meer JR (2008) Curr Opin Microbiol 11:205-212

18. Bergquist P, Hardiman E, Ferrari B, Winsley T (2009) Extremophiles 3:389-401

19. Muirhead KA, Horan PK, Poste G (1985) Nat Biotechnol 3:337-356

20. Fouchet P, Jayat C, Hechard Y, Ratinaud MH, Frelat G (1993) Biol Cell 78:95-109

21. Vives-Rego J, Lebaron P, Nebe-von-Caron G (2000) FEMS Microbiol Rev 24:429-448

22. Gasol JM, del Giorgio PA (2000) Sci Mar 64:197-224

23. Lebaron P, Parthuisot N, Catala P (1998) Appl Environ Microbiol 64:1725-1730

24. Hammes FA, Egli T (2005) Environ Sci Technol 39:3289-3294

25. Hammes F, Berney M, Wang Y, Vital M, Köster O, Egli T (2008) Water Res 42:269-277

26. Robertson BR, Button DK (1989) Cytometry 10:70-76

27. Wang Y, Hammes F, Boon N, Chami M, Egli T (2009) ISME J 3:889-902

28. Koch AL, Robertson BR, Button DK (1996) J Microbiol Methods 27:49-61

29. Robertson BR, Button DK, Koch AL (1998) Appl Environ Microbiol 64:3900-3909

30. Servais P, Casamayor EO, Courties C, Catala P, Parthuisot N, Lebaron P (2003) Aquat Microb Ecol 33:41-51

31. Foladori P, Quaranta A, Ziglio G (2008) Water Res 42:37573766

32. Müller S, Sträber H, Lösche A, Babel W (2002) J Biotechnol 97:163-176

33. Müller S (2007) Cell Prolif 40:621-639

34. Weinbauer MG, Beckmann C, Höfle MG (1998) Appl Environ Microbiol 64:5000-5003

35. Shapiro HM (1981) Cytometry 2:143-150

36. Müller S, Ullrich S, Lösche A, Loffhagen N, Babel W (2000) J Microbiol Methods 40:667-677

37. Gasol JM, Zweifel UL, Peters F, Fuhrman JA, Hagstrom A (1999) Appl Environ Microbiol 65:4475-4483

38. Lebaron P, Servais P, Agogue H, Courties C, Joux F (2001) Appl Environ Microbiol 67:1775-1782

39. Li WKW, Jellett JF, Dickie PM (1995) Limnol Oceanogr 40:1485-1495

40. Nishimura Y, Kim C, Nagata T (2005) Appl Environ Microbiol 71:5828-5836

41. Wang Y, Hammes F, Egli T (2008) Water Res 42:4319-4326 
42. Longnecker K, Sherr BF, Sherr EB (2005) Appl Environ Microbiol 71:7737-7749

43. Lebaron P, Servais P, Baudoux AC, Bourrain M, Courties C, Parthuisot N (2002) Aquat Microb Ecol 28:131-140

44. Phe MH, Dossot M, Guilloteau H, Block JC (2005) Water Res 39:3618-3628

45. Bouvier T, Del Giorgio PA, Gasol JM (2007) Environ Microbiol 9:2050-2066

46. Falcioni T, Papa S, Campana R, Manti A, Battistelli M, Baffone W (2008) Cytometry B Clin Cytom 74:272-281

47. Berney M, Vital M, Hülshoff I, Weilenmann H-U, Egli T, Hammes F (2008) Water Res 42:4010-4018

48. Lahtinen SJ, Ouwehand AC, Reinikainen JP, Korpela JM, Sandholm J, Salminen SJ (2006) Appl Environ Microbiol 72:5132-5134

49. Novo DJ, Perlmutter NG, Hunt RH, Shapiro HM (2000) Antimicrob Agents Chemother 44:827-834

50. Berney M, Weilenmann H-U, Egli T (2006) Microbiology 152:1719-1729

51. Bosshard F, Berney M, Scheifele M, Weilenmann H-U, Egli T (2009) Microbiology 155:1310-1317

52. Hewitt CJ, Nebe-von-Caron G, Axelsson B, McFarlane CM, Nienow AW (2000) Biotechnol Bioeng 70:381-390

53. Berney M, Hammes F, Bosshard F, Weilenmann H-U, Egli T (2007) Appl Environ Microbiol 73:3283-3290

54. Porter J, Deere D, Pickup R, Edwards C (1996) Cytometry 23:91-96

55. Shi L, Gunther S, Hubschmann T, Wick LY, Harms H, Müller S (2007) Cytometry Part A 71:592-598

56. Villarino A, Rager M-N, Grimont PA, Bouvet OMM (2003) Eur J Biochem 270:2689-2695

57. Donnelly CW, Baigent GJ (1986) Appl Environ Microbiol 52:689-695

58. Phillips AP, Martin KL (1988) J Immunol Methods 106:109-117

59. Hahn MA, Keng PC, Krauss TD (2008) Anal Chem 80:863-872

60. Vital M, Hammes F, Egli T (2008) Environ Microbiol 10:2387-2396

61. Füchslin HP, Kötzsch S, Keserue H-A, Egli T (2010) Cytometry Part A 77A:264-274

62. Vital M, Füchslin HP, Hammes F, Egli T (2007) Microbiology 153:1993-2001

63. Clarke RG, Pinder AC (1998) J Appl Microbiol 84:577-584

64. Gerdts G, Luedke G (2006) J Microbiol Methods 64:232-240

65. Lenaerts J, Lappin-Scott HM, Porter J (2007) Appl Environ Microbiol 73:2020-2023

66. Zahavy E, Heleg-Shabtai V, Zafrani Y, Marciano D, Yitzhaki S (2010) J Fluoresc (in press)
67. Li Z, Bai GH, von Reyn CF, Marino P, Brennan MJ, Gine N, Morris SL (1996) J Clin Microbiol 34:1903-1907

68. Amigliani G, Omicciolo E, del Campo A, Bruce IJ, Grandi G, Magnani M (2006) J Appl Microbiol 100:375-383

69. Aurell H, Catala P, Farge P, Wallet F, Le Brun M, Helbig JH, Jarraud S, Lebaron P (2004) Appl Environ Microbiol 70:1651-1657

70. Weeks ME, Nebe-von-Caron G, James DC, Smales CJ, Robinson GK (2006) J Microbiol Methods 43:46-55

71. Ferrari BC, Oregaard G, Sorensen SJ (2004) Microb Ecol 48:239-245

72. Bakker-Schut TC, De Grooth BG, Greve J (1993) Cytometry 13:649-659

73. Boddy L, Wilkins MF, Morris CW (2001) Cytometry 44:195-201

74. Günther S, Hübschmann T, Rudolf M, Eschenhagen M, Röske I, Harms H, Müller S (2008) J Microbiol Methods 75:127-134

75. Rieseberg M, Kasper C, Reardon KF, Scheper T (2001) Appl Microbiol Biotechnol 56:350-360

76. Bartram J, Cotruvo J, Exner M, Fricker C, Glasmacher A (2003) Heterotrophic plate counts and drinking-water safety. IWA Publishing, London

77. Rosenfeldt EJ, Baeza C, Knappe DRU (2009) J Am Water Works Assoc 101:60-70

78. Hoefel D, Grooby WL, Monis PT, Andrews S, Saint CP (2003) J Microbiol Methods 55:585-597

79. Ziglio G, Andreottola G, Barbesti S, Boschetti G, Bruni L, Foladori P, Villa R (2002) Water Res 36:460-468

80. Thyssen M, Mathieu D, Garcia N, Denis M (2008) J Plankton Res 30:1027-1040

81. Maukonen J, Alakomi HL, Nohynek L, Hallamaa K, Leppamaki S, Matto J, Saarela M (2006) Food Res Int 39:22-32

82. Looser V, Hammes F, Keller M, Berney M, Kovar K, Egli T (2005) Biotechnol Bioeng 92:69-78

83. Ateya DA, Erickson JS, Howell PB, Hilliard LR, Golden JP, Ligler FS (2008) Anal Bioanal Chem 391:1485-1498

84. Suller MTE, Lloyd D (1999) Cytometry Part 35:235-241

85. Wallner G, Amann R, Beisker W (1993) Cytometry 14:136-143

86. Ingram M, Cleary TJ, Priece RL, Castro A (1982) Cytometry Part A 3:134-137

87. Tyndall RL, Hand RE, Mann RC, Evans C, Jernigan R (1985) Appl Environ Microbiol 49:852-857

88. Pinder AC, McClelland RG (1994) J Microsc 176:17-22

89. Nexmann Jacobsen C, Fremming C, Jakobsen M (1997) J Microbiol Methods 31:75-81

90. Deng MW, Lam KM, Cliver DO (2000) J Microbiol Methods 40:11-17

91. Ferrari BC, Veal D (2003) Cytometry Part A 51:79-86 